\title{
Uncaria alkaloids reverse ABCB1-mediated cancer multidrug resistance
}

\author{
BAO-YUAN HUANG ${ }^{*}$, YU ZENG ${ }^{1 *}$, YING-JIE LI $^{2}$, XIAO-JUN HUANG ${ }^{2}$, NAN HU $^{2}$, NAN YAO $^{2}$, \\ MIN-FENG CHEN ${ }^{2}$, ZAI-GANG YANG ${ }^{3}$, ZHE-SHENG CHEN ${ }^{2}$, DONG-MEI ZHANG ${ }^{2}$ and CHANG-QING ZENG ${ }^{1}$ \\ ${ }^{1}$ National Administration of Traditional Chinese Medicine Key Laboratory of Chinese Medicine Digital Quality \\ Evaluation Technology, College of Traditional Chinese Medicine, Guangdong Pharmaceutical University, \\ Guangzhou, Guangdong 510006; ${ }^{2}$ Institute of Traditional Chinese Medicine and Natural Products, \\ College of Pharmacy, Jinan University, Guangzhou, Guangdong 510632; ${ }^{3}$ Institute of Uncaria, \\ Jianhe Science and Technology Bureau, Jianhe, Guizhou 556400, P.R. China
}

Received February 8, 2017; Accepted April 24, 2017

DOI: $10.3892 /$ ijo.2017.4005

\begin{abstract}
The overexpression of ATP-binding cassette (ABC) transporters is the main cause of cancer multidrug resistance (MDR), which leads to chemotherapy failure. Uncaria alkaloids are the major active components isolated from uncaria, which is a common Chinese herbal medicine. In this study, the MDR-reversal activities of uncaria alkaloids, including rhynchophylline, isorhynchophylline, corynoxeine, isocorynoxeine (Icory), hirsutine and hirsuteine, were screened; they all exhibited potent reversal efficacy when combined with doxorubicin. Among them, Icory significantly sensitized ABCB1-overexpressing HepG2/ADM and MCF-7/ADR cells to vincristine, doxorubicin and paclitaxel, but not to the
\end{abstract}

Correspondence to: Professor Dong-Mei Zhang, Institute of Traditional Chinese Medicine and Natural Products, College of Pharmacy, Jinan University, 601 West Huangpu Avenue, Guangzhou, Guangdong 510632, P.R. China

E-mail:dmzhang701@foxmail.com

Professor Chang-Qing Zeng, National Administration of Traditional Chinese Medicine Key Laboratory of Chinese Medicine Digital Quality Evaluation Technology, College of Traditional Chinese Medicine, Guangdong Pharmaceutical University, 280 East Road, Outer Ring, Guangzhou Higher Education Mega Center, Guangzhou, Guangdong 510006, P.R. China

E-mail: gdzcq@163.com

${ }^{*}$ Contributed equally

Abbreviations: ABC transporter, ATP-binding cassette transporter; Cory, corynoxeine; DOX, doxorubicin; FTC, fumitremorgin C; HS, hirsutine; HST, hirsuteine; Icory, isocorynoxeine; Irhy, isorhynchophylline; MDR, multidrug resistance; MX, mitoxantrone; qRT-PCR, quantitative real-time PCR; Rhy, rhynchophylline; VCR, vincristine; VRP, verapamil

Key words: Unicaria alkaloids, ABC transporters, ABCB1, multidrug resistance
non-ABCB1 substrate cisplatin. Noteworthy, Icory selectively reversed $\mathrm{ABCB} 1$-overexpressing $\mathrm{MDR}$ cancer cells but not ABCC1- or ABCG2-mediated MDR. Further mechanistic study revealed that Icory increased the intracellular accumulation of doxorubicin in ABCB1-overexpressing cells by blocking the efflux function of ABCB1. Instead of inhibiting ABCB1 expression and localization, Icory acts as a substrate of the ABCB1 transporter by competitively binding to substrate binding sites. Collectively, these results indicated that Icory reversed ABCB1mediated MDR by suppressing its efflux function, and it would be beneficial to increase the efficacy of these types of uncaria alkaloids and develop them to be selective ABCB1-mediated MDR-reversal agents.

\section{Introduction}

Multidrug resistance (MDR) is the main cause of chemotherapeutic treatment failure in cancer patients. As a difficult problem, combating MDR cancer has always been an important mission of oncotherapy. The mechanisms of MDR are complex and obscure $(1,2)$. The major mechanism of MDR involves the overexpression of ATP-binding cassette (ABC) transporters. The ABC family of transporters comprises 49 members that are subdivided into seven subfamilies, ABC-A to $\mathrm{ABC}-\mathrm{G}$, based on their sequences and structures. Among known $\mathrm{ABC}$ transporters, $\mathrm{ABCB} 1, \mathrm{ABCC} 1$ and $\mathrm{ABCG} 2$ are the most influential members in MDR cancer $(3,4)$. ABCB1 (P-glycoprotein), encoded by the MDR1 gene, is a $170-\mathrm{kDa}$ apical plasma membrane protein comprising two homologous halves, each containing an ATP-binding domain and six transmembrane helices $(5,6)$. ABCB1 is an ATP-dependent drug efflux pump that can transport a wide range of amphipathic and hydrophobic anticancer drugs, such as doxorubicin (DOX), vincristine (VCR), paclitaxel, epipodophyllotoxins, anthracyclines and taxanes (7). Thus, antitumor agents that are $\mathrm{ABCB} 1$ substrates and are used in long-term treatment subsequently stimulate cancer cells to upregulate the ABCB1 mRNA copy number. The overexpression of ABCB1 results in decreased intracellular antineoplastic drug concentrations to sub-toxic levels. Thus, resensitizing MDR cancer cells to 
anticancer drugs using inhibitors that block the efflux system may be a successful chemotherapeutic strategy. However, in the past three decades, most ABCB1 modulators have failed in clinical trials due to their low binding affinities, excessive toxicity or non-specificity (8-12). Thus, the identification of new ABCB1 transporter inhibitors with lower toxicity but greater potency and specificity is extremely urgent.

Uncaria, a traditional Chinese medicine, is a member of the Uncaria rhynchophylla (Miq.) Jacks. family and is used to treat neoplastic diseases, various cerebrovascular diseases, nervous disorders and symptoms associated with hypertension, epilepsy, stroke and preeclampsia $(13,14)$. Various active constituents have been isolated, such as alkaloids, flavonoids, sterols, coumarins, terpenoids and terpenoid glycosides (15). A number of alkaloids in uncaria are used for cancer treatment and adjuvant chemotherapy, among which rhynchophylline (Rhy), isorhynchophylline (Irhy), corynoxeine (Cory), isocorynoxeine (Icory), hirsutine (HS) and hirsuteine (HST) are the major components. The exact antitumor activities and mechanisms of these uncaria alkaloids remain to be identified.

Herein, six uncaria alkaloids were preliminarily screened, and all these compounds exhibited potential MDR-reversal activity. Among them, Icory had the strongest activity. Therefore, we used Icory as a representative compound to study in depth its MDR-reversal activity and to further clarify its underlying mechanisms.

\section{Materials and methods}

Chemicals and reagents. Rhy, Irhy, Cory, Icory, HS and HST were purchased from YUANYE (Shanghai, China), and their purities determined by HPLC were $>98 \%$. VCR, DOX, paclitaxel and cisplatin were purchased from Selleck Chemicals (Houston, TX, USA). The Pgp-Glo ${ }^{\mathrm{TM}}$ assay kit was purchased from Promega (Fitchburg, WI, USA). The Quanscript RT kit and Multi-PCR kit were obtained from Multisciences (Hangzhou, Zhejiang, China). Mouse anti-ABCB1 antibody was purchased from Santa Cruz Biotechnology, Inc. (Dallas, TX, USA). Mouse anti- $\beta$-actin antibody was acquired from Cell Signaling Technology (Beverly, MA, USA). Verapamil (VRP), Fumitremorgin C (FTC), Mitoxantrone (MX), MK-571, 3-(4,5-dimethylthiazol-yl)-2,5-diphenyllapatinibrazolium bromide (MTT), 2-(4-amidinophenyl)-6-indolecarbamidene dihydrochloride (DAPI), dimethyl sulfoxide (DMSO) and other chemicals were obtained from Sigma-Aldrich (St. Louis, MO, USA).

Cell lines and cell culture. The human hepatocellular carcinoma cell line HepG2 and the ABCB1-overexpressing cell line HepG2/ADM were kindly provided by Professor Kwok-Pui Fung (The Chinese University of Hong Kong, Hong Kong, China). The human breast cancer cell line MCF-7 and its doxorubicin-selected ABCB1-overexpressing cell line MCF-7/ADR were previously provided by Professor Li-Wu Fu (Sun Yat-Sen University, Guangzhou, China). The human primary embryonic kidney cell line HEK293 and its pcDNA3.1, ABCB1-transfected cell lines HEK293/pcDNA3.1 and HEK293/MRP1 were kindly provided by Dr Suresh Ambudkar (NCI, NIH, Bethesda, MD, USA). The colorectal cancer cell line S1 and ABCG2 overexpressing
S1-M1-80 cells were kindly provided by Dr Susan Bates and Robert Robey (NCI, NIH, Bethesda, MD, USA). All of the cell lines were maintained in DMEM supplemented with $10 \%$ fetal bovine serum and $1 \%$ penicillin-streptomycin in a humidified incubator containing $5 \% \mathrm{CO}_{2}$ at $37^{\circ} \mathrm{C}$. HepG2/ADM and MCF-7/ADR cells were cultured in media containing $1.2 \mu \mathrm{M}$ DOX to maintain their resistance features.

Cytotoxicity determination by the MTT assay. The MTT assay was used to detect the cytotoxic activity and MDR-reversal activity of uncaria alkaloids and VRP. Cells (5x10\%/well) were distributed into 96-well plates and were maintained overnight. For the cytotoxicity experiments, cells were cultured with different concentrations of uncaria alkaloids (Rhy, Irhy, Cory, Icory, HS and HST) or with VRP for $72 \mathrm{~h}$. To evaluate the reversal activity of these alkaloids, various concentrations of the chemotherapeutic drugs with or without alkaloids at sub-toxic concentrations were added into the designated wells. After $72 \mathrm{~h}$ of incubation, $30 \mu \mathrm{l}$ of MTT $(5 \mathrm{mg} / \mathrm{ml})$ was added to each well, and the plates were further incubated at $37^{\circ} \mathrm{C}$ for $4 \mathrm{~h}$. The medium was then removed, and $100 \mu \mathrm{l}$ of DMSO was added into each well to dissolve the formazan crystals. The absorbance was read at $570 \mathrm{~nm}$ using a DTX 880 Multimode Detector (Beckman Coulter, Brea, CA, USA). The $\mathrm{IC}_{50}$ value was calculated from the survival curves using GraphPad Prism 5.0 software. The reversal fold was calculated by dividing the $\mathrm{IC}_{50}$ of antineoplastic agents alone by the $\mathrm{IC}_{50}$ of antineoplastic agents in the presence of alkaloids. VRP was used as a positive control.

Microscopic observation of intracellular DOX. HepG2/ADM and MCF-7/ADR cells were seeded into 35-mm dishes for $24 \mathrm{~h}$ before being pretreated with Icory or VRP for $2 \mathrm{~h}$, then $10 \mu \mathrm{M}$ DOX were added and further co-incubated with modulators for $2 \mathrm{~h}$. Subsequently, the cells were washed with PBS and fixed with $4 \%$ paraformaldehyde. DAPI was used to stain the nuclei. Cellular DOX fluorescence was detected by fluorescence microscopy (Axio Imager A2, Zeiss, Jena, Germany).

DOX accumulation assay. To measure the accumulation of DOX, $2 \times 10^{4}$ cells/well were seeded in 96-well plates for $24 \mathrm{~h}$. Cells were pretreated with Icory $(25$ and $50 \mu \mathrm{M})$ or VRP $(50 \mu \mathrm{M})$ at $37^{\circ} \mathrm{C}$ for $2 \mathrm{~h}$ and were then incubated with DOX at a concentration of $10 \mu \mathrm{M}$ in the absence or presence of modulators for $2 \mathrm{~h}$ at $37^{\circ} \mathrm{C}$. Subsequently, the medium was discarded, and the cells were washed three times with ice-cold PBS and soaked in $50 \mu \mathrm{l}$ of PBS. The fluorescence value of DOX was detected using a DTX 880 Multimode Detector (Beckman Coulter), and the excitation and emission wavelengths of DOX were 488 and $535 \mathrm{~nm}$, respectively.

DOX efflux assay. Cells ( $5 \times 10^{3}$ per well) were distributed into 96-well plates and incubated for $24 \mathrm{~h}$ before being pretreated with $25 \mu \mathrm{M}$ DOX at $37^{\circ} \mathrm{C}$ for $2 \mathrm{~h}$, after which time the cells were supplemented with reversal agents (Icory or VRP). After various time points $(0,30,70,130 \mathrm{~min})$, the cell culture supernatant was discarded, and the cell cultures were immediately washed three times with ice-cold PBS. The cells were fixed with paraformaldehyde for the detection of radioactivity, in a routine manner. 
Real-time fluorescence quantitative PCR assay. A real-time fluorescence quantitative PCR (qRT-PCR) assay was used to determine the mRNA expression of ABCB1. HepG2/ADM or MCF-7/ADR cells (5x10 /well) were seeded in 6-well plates and were treated with various concentrations of Icory for $24 \mathrm{~h}$ or $48 \mathrm{~h}$. Total RNA was then collected using a TRIzol kit (Qiagen, Hilden, Germany) according to the manufacturer's protocol. cDNA was reverse transcribed from $1 \mu \mathrm{g}$ of total RNA using a reverse transcription kit (Roche, Mannheim, Germany), and the forward and reverse primers used in the qRT-PCR were as follows: 5'-CAGAGTCAAGGAGCATG GCA-3 (MDR1 forward primer), 5'-TCAGAGTTCACTGGC GCTTT-3 (MDR1 reverse primer); GAPDH-F: 5'-GAAGGTG AAGGTCGGAGTC-3', GAPDH-R: 5'-GAAGATGGTGAT GGGATTTC-3'. Amplification was performed according to the instructions for the SYBR Green Master Mix (Roche) using a Roche LightCycler (Basel, Basel-Stadt, Switzerland). PCR was performed at $95^{\circ} \mathrm{C}$ for $10 \mathrm{sec}$ of initial denaturation and then at $60^{\circ} \mathrm{C}$ for $20 \mathrm{sec}, 72^{\circ} \mathrm{C}$ for $20 \mathrm{sec}$ for 45 cycles. Relative expression levels were calculated using the $2^{-\Delta \Delta \mathrm{Ct}}$ method for qRT-PCR.

Western blotting. Cells were collected after incubation with 25 or $50 \mu \mathrm{M}$ Icory for 24 or $48 \mathrm{~h}$, lysed with RIPA lysis buffer (10 mM Tris $\mathrm{HCl} \mathrm{pH} 7.5,1 \mathrm{mM}$ EDTA, 0.1\% SDS, $150 \mathrm{mM} \mathrm{NaCl}, 1 \%$ Triton $\mathrm{X}-100$ and $0.01 \%$ leupeptin) for $0.5 \mathrm{~h}$ and centrifuged at $14,000 \mathrm{x} \mathrm{g}$ at $4^{\circ} \mathrm{C}$ for $10 \mathrm{~min}$. The supernatant was stored at $-80^{\circ} \mathrm{C}$ until gel electrophoresis. Protein concentrations were detected using the bicinchoninic acid (BCA)-based protein assay (Thermo Scientific, Rockford, IL, USA). A total of $30 \mu \mathrm{g}$ of protein from the cell lysates was separated by $10 \%$ SDS-PAGE and transferred onto a PVDF membrane (Millipore, Billerica, MA, USA). The membranes were blocked in blocking buffer (5\% non-fat dry milk in TBST buffer) and were then immunoblotted with ABCB1 antibody (1:500) overnight at $4^{\circ} \mathrm{C}$. After washing three times with TBST buffer, the membranes were further incubated for $1 \mathrm{~h}$ at room temperature with HRP-conjugated secondary antibody $(1: 2,000)$. Protein detection on the blot was performed using an enhanced chemiluminescence detection kit (Beyotime Institute of Biotechnology, Shanghai, China).

Immunofluorescence assay. Cells $\left(1 \times 10^{5}\right)$ were incubated with $50 \mu \mathrm{M}$ of Icory for 24 and $48 \mathrm{~h}$, respectively. Then cells were washed thrice with PBS and fixed with $4 \%$ paraformaldehyde for $20 \mathrm{~min}$ at room temperature. Subsequently, cells were blocked with 5\% BSA for $1 \mathrm{~h}$ at room temperature, followed by monoclonal antibody (1:50) against ABCB1 at $4^{\circ} \mathrm{C}$ overnight. After that cells were rinsed with PBS and then stained with Alexa fluor 488-conjugated goat anti-mouse secondary antibody (1:500) for $1 \mathrm{~h}$ at room temperature in the dark. DAPI $(1 \mu \mathrm{g} / \mu \mathrm{l})$ was used to counterstain the nuclei. Images were taken by a confocal microscope (LSM 700, Zeiss) at 495-nm excitation and 519-nm emission wavelength (FITC 488) and 340-nm excitation and 488-nm emission wavelength (DAPI).

ABCB1 ATPase assay. The ABCB1-Glo ${ }^{\mathrm{TM}}$ ATPase assay was used to detect the effects of Icory on recombinant human
Table I. Reversal activity of six uncaria alkaloids in HepG2/ADM cells and their parental cells.

\begin{tabular}{lcc}
\hline & \multicolumn{2}{c}{$\mathrm{IC}_{50} \pm \mathrm{SD}^{\mathrm{a}}(\mu \mathrm{M})\left(\right.$ fold-reversal $\left.^{\mathrm{b}}\right)$} \\
\cline { 2 - 3 } Treatments & HepG2/ADM & HepG2 \\
\hline DOX & $78.5314 \pm 9.7768(1.00)$ & $0.3357 \pm 0.0193(1.00)$ \\
+ Rhy $50 \mu \mathrm{M}$ & $5.4859 \pm 2.7101(14.32)$ & $0.3852 \pm 0.1186(0.87)$ \\
+ Irhy $50 \mu \mathrm{M}$ & $3.9646 \pm 1.1056(19.81)$ & $0.3678 \pm 0.0261(0.91)$ \\
+ Cory $50 \mu \mathrm{M}$ & $5.2865 \pm 0.7767(14.86)$ & $0.3278 \pm 0.1221(1.02)$ \\
+ Icory $50 \mu \mathrm{M}$ & $2.5256 \pm 0.6897(31.09)$ & $0.3653 \pm 0.0849(0.92)$ \\
+ HS $3 \mu \mathrm{M}$ & $15.2977 \pm 0.7666(5.13)$ & $0.3982 \pm 0.0796(0.84)$ \\
+ HST $3 \mu \mathrm{M}$ & $14.3615 \pm 2.0456(5.47)$ & $0.4124 \pm 0.0153(0.81)$ \\
\hline
\end{tabular}

${ }^{\text {aD }}$ Data in the table are shown as means \pm SD of three independent experiments performed in six replicates. ${ }^{b}$ The fold-reversals are calculated as $\mathrm{IC}_{50}$ for cells with the anticancer drug in the absence of inhibitors divided by that in the presence of inhibitors.

ABCB1. The ABCB1 ATPase inhibitor $\mathrm{Na}_{3} \mathrm{VO}_{4}(250 \mu \mathrm{M})$, $\operatorname{VRP}(500 \mu \mathrm{M})$ and Icory $(25,50$ and $100 \mu \mathrm{M})$ were prepared and added to untreated white polystyrene 96-well plates, and then ABCB1-containing membranes were added to each well and incubated at $37^{\circ} \mathrm{C}$ for approximately $5 \mathrm{~min}$. The reactions were initiated by adding $10 \mu \mathrm{l}$ of $\operatorname{MgATP}(25 \mathrm{mM})$ and were then incubated for $40 \mathrm{~min}$ at $37^{\circ} \mathrm{C}$. The plate was removed from $37^{\circ} \mathrm{C}$, and luminescence was initiated by adding $50 \mu 1$ of Detection Reagent. Next, the plate was incubated at room temperature for $20 \mathrm{~min}$ to stabilize the luminescent signal, and the luminescence was read on a DTX880 Multimode Detector (Beckman Coulter).

Duration of MDR-reversal effect assay. The durations of Icory and VRP reversal effects were measured as previously described (16). HepG2/ADM cells $\left(5 \times 10^{3}\right.$ cells) were pretreated with Icory or VRP at a concentration of $50 \mu \mathrm{M}$ for $24 \mathrm{~h}$. In the durative group, the MDR modulators were removed, and the cells were washed with PBS and then treated with various concentrations of DOX. In the unwashed group, different concentrations of DOX were added to retain the MDR modulators. Cell viability was detected using the MTT assay, as described above.

Docking assay. The crystal structure of mouse ABCB1 was obtain from the protein data bank (PDB entry code: 3G5U), which was further prepared by using Surflex-Dock in Sybyl 8.0. Halved structure of $3 \mathrm{G} 5 \mathrm{U}$ was used as the receptor in the following docking experiment. The low-energy 3D structure of Icory and VPR was generated based on the random conformational search with restricted chirality, which was performed using the standard MMFF94s molecular mechanics force field and MMFF94 charge. Optimized 3D structures of VRP and Icory were docked into the binding site of ABCB1 by using Surflex-dock in Sybyl 8.0 to simulate the binding modes. The best docking score was used in the docking process to identify the preferable conformation of Icory and ABCB1. Icory and VRP were docked into the 
A<smiles>CO/C=C(/C(=O)OC)[C@H]1CCN2CC[C@@]3(C(=O)Nc4ccccc43)[C@@H]2C1</smiles>

Rhynchophylline $(\mathrm{R}=\mathrm{Et})$

Corynoxeine $\left(\mathrm{R}=\mathrm{CH}=\mathrm{CH}_{2}\right)$

B

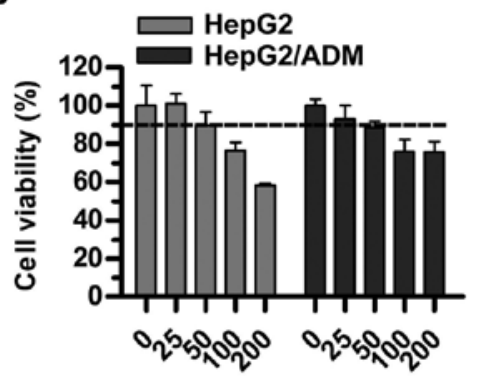

Rhy concentration $(\mu \mathrm{M})$

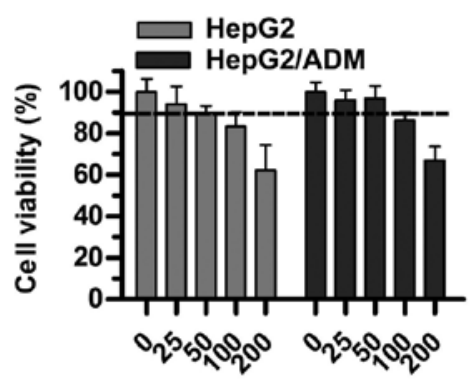

Icory concentration $(\mu \mathrm{M})$

C

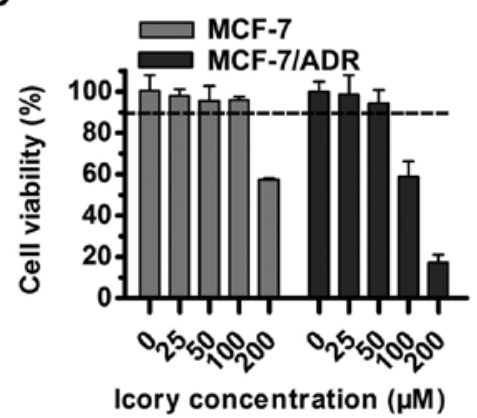

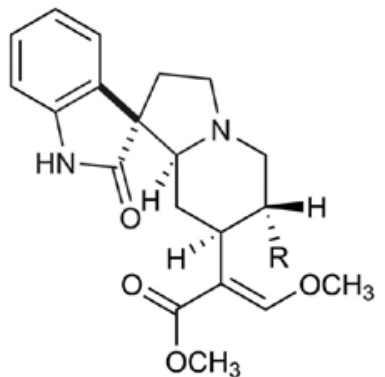

Isorhynchophylline $(\mathrm{R}=\mathrm{Et})$ Isocorynoxeine $\left(\mathrm{R}=\mathrm{CH}=\mathrm{CH}_{2}\right)$<smiles>[R]O/C=C(/C(=O)OC)[C@H]1CCN2CCc3c([nH]c4ccccc34)[C@@H]2C1</smiles>

Hirsutine $(\mathrm{R}=\mathrm{Et})$

Hirsuteine $\left(\mathrm{R}=\mathrm{CH}=\mathrm{CH}_{2}\right)$

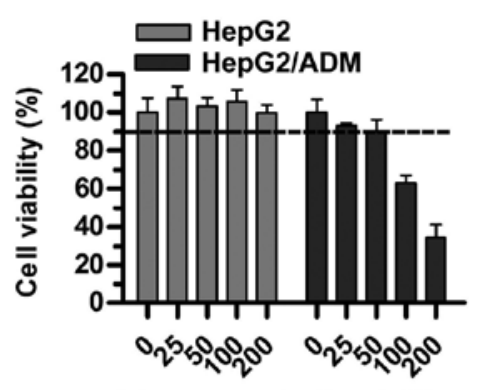

Irhy concentration $(\mu \mathrm{M})$

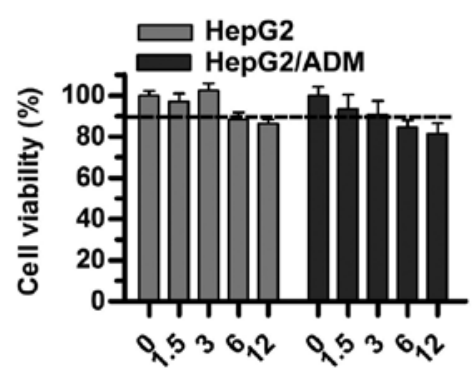

HS concentration $(\mu \mathrm{M})$

D

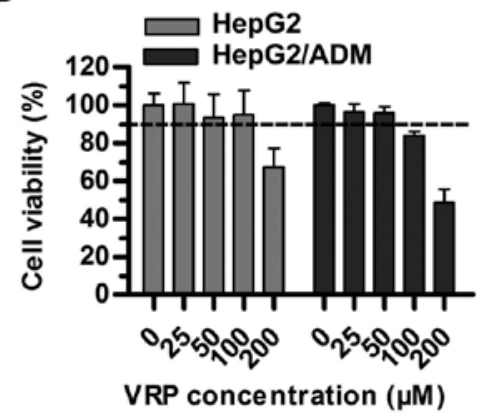

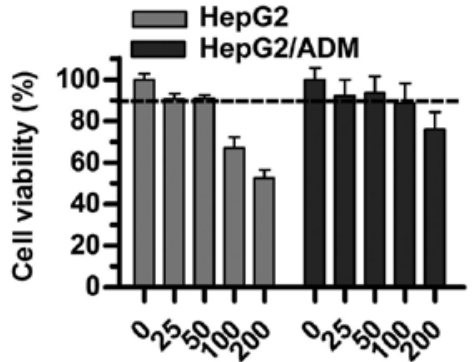

Cory concentration ( $\mu \mathrm{M})$

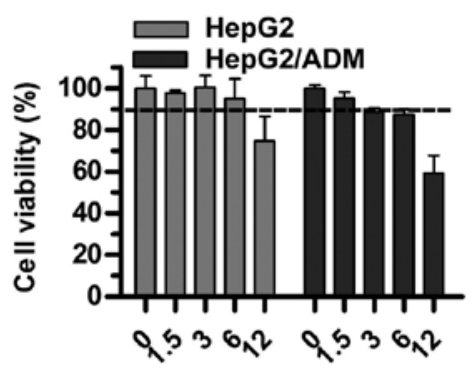

HST concentration $(\mu \mathrm{M})$

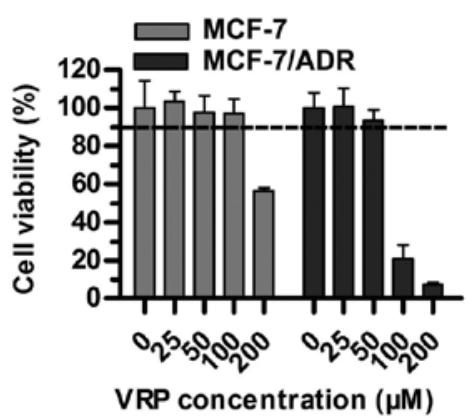

Figure 1. Cytotoxicity assays of individual uncaria alkaloids (Rhy, Irhy, Cory, Icory, HS and HST) and VRP in ABCB1-overexpressing cells and in their parental cells. (A) The chemical structures of Rhy, Irhy, Cory, Icory, HS and HST. (B) The percentage of surviving cells was measured after treatment with Rhy, Irhy, Cory, Icory, HS and HST for $72 \mathrm{~h}$ in ABCB1-overexpressing cells and their parental cells, namely, HepG2/ADM and HepG2 cells, respectively. (C) The cell survival percentage was measured after treatment with Icory for $72 \mathrm{~h}$ in MCF-7/ADR and MCF-7 cells. (D) The cell survival percentage was measured after treatment with VRP for $72 \mathrm{~h}$ in HepG2/ADM, HepG2 cells, MCF-7/ADR and MCF-7 cells. The results were presented as the means \pm SD of three independent experiments performed in six replicates.

binding site of $\mathrm{ABCB} 1$ according to their best docking scores, and further interactions and binding energy were analyzed.

Data analysis. Every experiment was repeated at least three times, and values are shown as the mean $\pm \mathrm{SD}$. The data were analyzed using GraphPad Prism 5.0, and the differences between two groups were analyzed by Student's t-test. The $\mathrm{P}$-value significance threshold was set at $\mathrm{P}<0.05$.

\section{Results}

Cytotoxicity of uncaria alkaloids and VRP in sensitive and resistant cells. The sub-cytotoxic concentrations (cell survival 
A
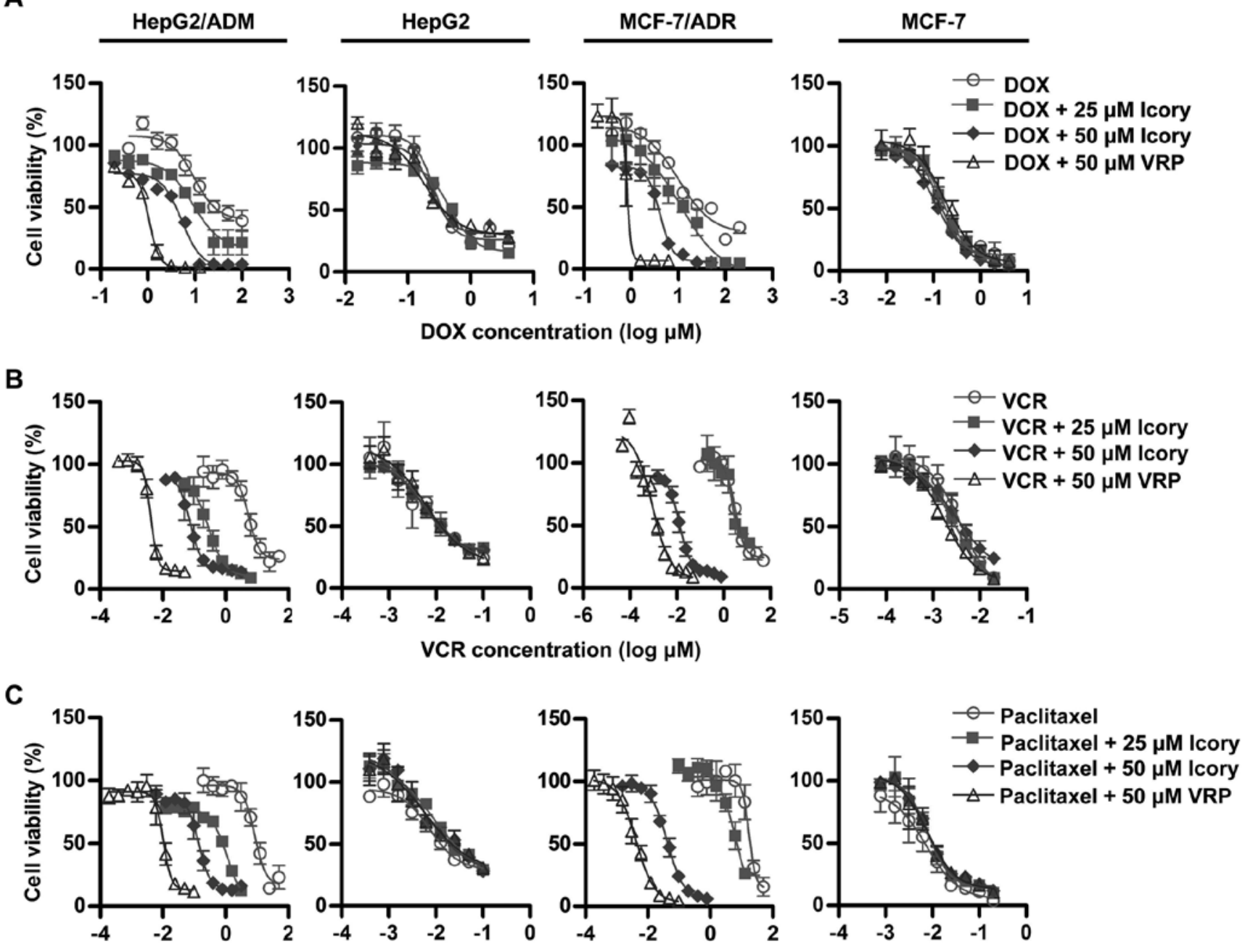

Paclitaxel concentration $(\log \mu \mathrm{M})$
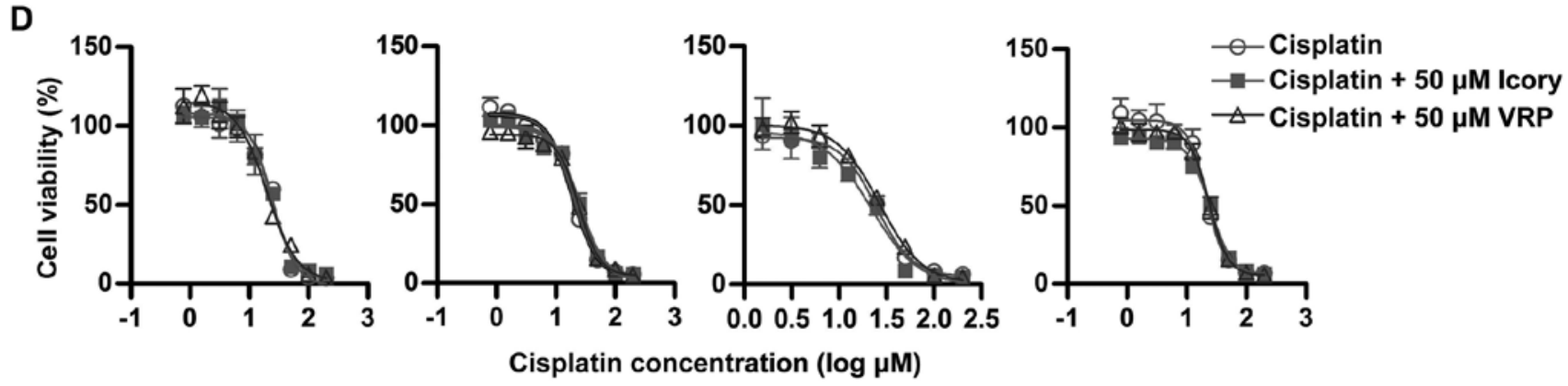

Figure 2. Icory sensitizes HepG2/ADM and MCF-7/ADR cells, but not their parental cells, to DOX, VCR and paclitaxel. The viability of HepG2/ADM, MCF-7/ADR cells and their parental cells treated with DOX (A), VCR (B), paclitaxel (C) and cisplatin (D) in the absence or presence of Icory (25 and $50 \mu \mathrm{M})$ was detected by the MTT assay. VRP $(50 \mu \mathrm{M})$ was used as a positive inhibitor of ABCB1. The results are presented as the means \pm SD of three independent experiments performed in six replicates.

rate of at least $90 \%$ ) of uncaria alkaloids (Rhy, Irhy, Cory, Icory, HS and HST) and VRP in sensitive and resistant cell lines were determined. A concentration of $50 \mu \mathrm{M}$ rather than $100 \mu \mathrm{M}$ met the requirement for Rhy, Irhy, Cory and Icory (Fig. 1B). A surprising finding was that HS and HST showed potential antitumor activity in HepG2/ADM cells and in the sensitive parental cell line HepG2, and their sub-cytotoxic concentrations fell to $3 \mu \mathrm{M}$ (Fig. 1B). To further test the reversal activity and to explore the underlying mechanisms of Icory, a pair of DOX-resistant and -sensitive cell lines, MCF-7/ADR and MCF-7, were chosen. Similarly, a non-toxic concentration of Icory in MCF-7/ADR and MCF-7 cells was $50 \mu \mathrm{M}$ (Fig. 1C). Therefore, concentrations of 25 and $50 \mu \mathrm{M}$ Icory were used for the subsequent MDR-reversal experiments. As a positive control, VRP at $50 \mu \mathrm{M}$ showed no toxicity to the four cell lines (Fig. 1D).

Uncaria alkaloids sensitize ABCB1-overexpressing cells to $D O X$. To investigate whether uncaria alkaloids had the ability to reverse ABCB1-mediated MDR, DOX was used as 
Table II. Reversal effect of Icory on HepG2/ADM, MCF-7/ADR and their parental sensitive cells.

$$
\mathrm{IC}_{50} \pm \mathrm{SD}^{\mathrm{a}}(\mu \mathrm{M})\left(\text { fold-reversal }{ }^{\mathrm{b}}\right)
$$

\begin{tabular}{lcccc}
\cline { 2 - 5 } Treatments & HepG2/ADM & HepG2 & MCF-7/ADR & MCF-7 \\
\hline DOX & $78.5314 \pm 9.7768(1.00)$ & $0.3357 \pm 0.0193(1.00)$ & $27.9157 \pm 0.8581(1.00)$ & $0.1921 \pm 0.0184(1.00)$ \\
+ Icory 25 $\mu \mathrm{M}$ & $9.3748 \pm 0.6148(8.38)$ & $0.3728 \pm 0.0467(0.90)$ & $13.8451 \pm 0.5140(2.02)$ & $0.1373 \pm 0.0064(1.39)$ \\
+ Icory 50 $\mu \mathrm{M}$ & $2.5256 \pm 0.6897(31.09)$ & $0.3653 \pm 0.0849(0.92)$ & $2.6711 \pm 0.6350(10.45)$ & $0.1913 \pm 0.0414(1.00)$ \\
+ VRP 50 $\mu \mathrm{M}$ & $1.1914 \pm 0.2304(65.92)$ & $0.3639 \pm 0.1987(0.91)$ & $0.6437 \pm 0.1536(43.37)$ & $0.1837 \pm 0.0415(1.05)$ \\
VCR & $5.6795 \pm 0.6825(1.00)$ & $0.0125 \pm 0.0018(1.00)$ & $6.4485 \pm 3.7066(1.00)$ & $0.0035 \pm 0.0013(1.00)$ \\
+ Icory 25 $\mu \mathrm{M}$ & $0.3408 \pm 0.2562(16.67)$ & $0.0128 \pm 0.0019(0.97)$ & $5.0590 \pm 1.3830(1.27)$ & $0.0043 \pm 0.0003(0.82)$ \\
+ Icory 50 $\mu \mathrm{M}$ & $0.1384 \pm 0.0988(41.04)$ & $0.0132 \pm 0.0030(0.94)$ & $0.0110 \pm 0.0083(584.10)$ & $0.0040 \pm 0.0014(0.88)$ \\
+ VRP 50 $\mu \mathrm{M}$ & $0.0037 \pm 0.0001(1525.93)$ & $0.0132 \pm 0.0001(0.94)$ & $0.0024 \pm 0.0016(2633.12)$ & $0.0026 \pm 0.0007(1.34)$ \\
Paclitaxel & $10.7748 \pm 2.2922(1.00)$ & $0.0222 \pm 0.0154(1.00)$ & $15.7079 \pm 2.6061(1.00)$ & $0.0093 \pm 0.0071(1.00)$ \\
+ Icory 25 $\mu \mathrm{M}$ & $0.6820 \pm 0.3245(15.80)$ & $0.0247 \pm 0.0008(0.90)$ & $7.7363 \pm 0.7618(2.03)$ & $0.0095 \pm 0.0012(0.98)$ \\
+ Icory 50 $\mu \mathrm{M}$ & $0.1462 \pm 0.0585(73.70)$ & $0.0227 \pm 0.0034(0.98)$ & $0.0467 \pm 0.0118(336.36)$ & $0.0093 \pm 0.0009(1.01)$ \\
+ VRP 50 $\mu \mathrm{M}$ & $0.0105 \pm 0.0024(1029.11)$ & $0.0207 \pm 0.0054(1.07)$ & $0.0033 \pm 0.0010(4783.16)$ & $0.0100 \pm 0.0013(0.93)$ \\
Cisplatin & $26.9154 \pm 0.08765(1.00)$ & $20.7555 \pm 0.5778(1.00)$ & $25.0096 \pm 1.2170(1.00)$ & $22.0492 \pm 1.0443(1.00)$ \\
+ Icory 50 $\mu \mathrm{M}$ & $26.0751 \pm 0.6919(1.03)$ & $23.4144 \pm 3.5658(0.87)$ & $20.6873 \pm 3.1638(1.21)$ & $18.7218 \pm 6.9056(1.18)$ \\
+ VRP 50 $\mu \mathrm{M}$ & $23.0622 \pm 0.0826(1.17)$ & $22.8127 \pm 1.4291(0.91)$ & $29.4822 \pm 3.2336(0.85)$ & $21.0994 \pm 4.1638(1.05)$ \\
\hline
\end{tabular}

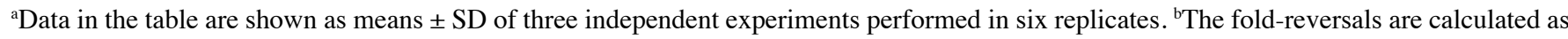
$\mathrm{IC}_{50}$ for cells with the anticancer drugs in the absence of inhibitors divided by that in the presence of inhibitors.

the anticancer drug in HepG2/ADM cells and in the parental HepG2 cells. The $\mathrm{IC}_{50}$ values of DOX with or without uncaria alkaloids in the two cell lines are shown in Table I. The results showed that each of the uncaria alkaloids variously increased the sensitivity of HepG2/ADM cells to DOX and that Icory exhibited the most potent activity, with a reversal-fold value of 31.09. Thus, Icory was chosen for the subsequent experiments as a representative of uncaria alkaloids.

Icory reverses $A B C B 1$-overexpressing cell resistance to $D O X$, $V C R$ and paclitaxel. The modulating effect of Icory was further examined in MDR cancer cell lines (HepG2/ADM and MCF-7/ ADR) and in their corresponding sensitive cell lines (HepG2 and MCF-7). The $\mathrm{IC}_{50}$ values of anticancer drugs (DOX, VCR, paclitaxel and cisplatin) in the ABCB1-overexpressing cells and in the parental cells with or without Icory are summarized in Table II. Consistent with the preliminary screening, Icory greatly enhanced the activity of DOX in DOX-resistant HepG2/ADM and MCF-7/ADR cells but not in their parental cell lines. Icory also increased the sensitivity of HepG2/ADM and MCF-7/ADR cells to VCR and paclitaxel, whereas this effect did not occur in their respective parental cell lines. However, the $\mathrm{IC}_{50}$ values of cisplatin were not altered in any of the cell lines when combined with Icory or VRP (Fig. 2). In the MCF-7/ADR cell line, Icory strikingly enhanced the toxicity of VCR and paclitaxel with 584.10 and 336.36 reversal-fold values, respectively. Collectively, these results indicated that Icory significantly reverses $\mathrm{ABCB} 1$-overexpressing cell resistance to DOX, VCR and paclitaxel.

Icory does not reverse $A B C C 1$ - or ABCG2-mediated MDR. Overexpressed $\mathrm{ABCC} 1$ and $\mathrm{ABCG} 2$ are two important
Table III. Reversal effect of Icory on HEK293/MRP1 and their parental sensitive cells.

\begin{tabular}{lcc}
\hline & \multicolumn{2}{c}{$\mathrm{IC}_{50} \pm \mathrm{SD}^{\mathrm{a}}(\mu \mathrm{M})\left(\right.$ fold-reversal $\left.^{\mathrm{b}}\right)$} \\
\cline { 2 - 3 } Treatments & HEK293/MRP1 & HEK293/pcDNA3.1 \\
\hline VCR & $4.2113 \pm 1.8257(1.00)$ & $0.0211 \pm 0.0062(1.00)$ \\
+ Icory $25 \mu \mathrm{M}$ & $6.0003 \pm 1.1998(0.70)$ & $0.0199 \pm 0.0055(1.06)$ \\
+ Icory $50 \mu \mathrm{M}$ & $4.5762 \pm 2.0726(0.92)$ & $0.0189 \pm 0.0089(1.12)$ \\
+ MK-571 $10 \mu \mathrm{M}$ & $0.1255 \pm 0.9248(33.56)$ & $0.0201 \pm 0.0057(1.05)$
\end{tabular}

${ }^{a}$ Data in the table are shown as means \pm SD of at least three independent experiments performed in six replicates. ${ }^{\text {b}}$ The fold-reversals are calculated as $\mathrm{IC}_{50}$ for cells with the anticancer drugs in the absence of inhibitors divided by that in the presence of inhibitors.

transporters in cancer MDR, and we further examined whether Icory exerted reversal effects on ABCC1- and ABCG2-overexpressing cell lines. First, we confirmed that Icory at $50 \mu \mathrm{M}$ showed no toxicity to the HEK293/MRP1 and S1-M1-80 cell lines or their parental cell lines (Fig. 3A). The ABCC1 modulator MK-571 significantly reversed the drug resistance of HEK293/MRP1 cells. However, we did not observe similar activity for Icory in HEK293/MRP1 cells when combined with the ABCC1 substrate VCR (Fig. 3B and Table III). Analogously, Icory had no reversal activity toward ABCG2-mediated MDR, as the $\mathrm{IC}_{50}$ values of MX in ABCG2overexpressing S1-M1-80 cells and their parental S1 cells were unchanged when co-treated with Icory. In stark contrast to 
A
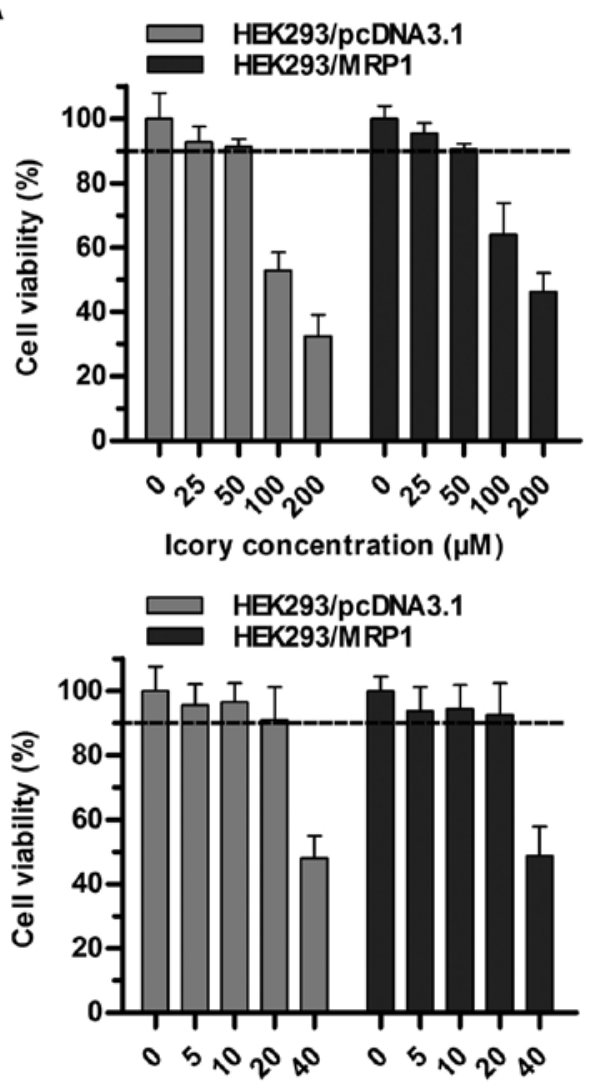

B

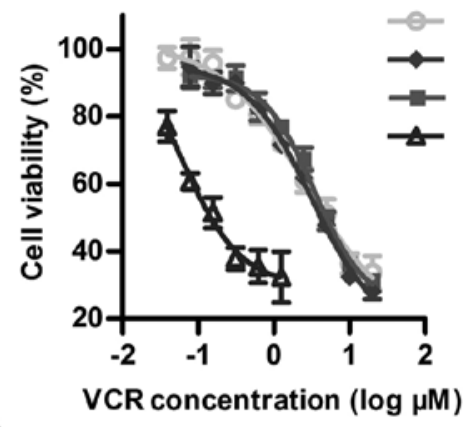

C

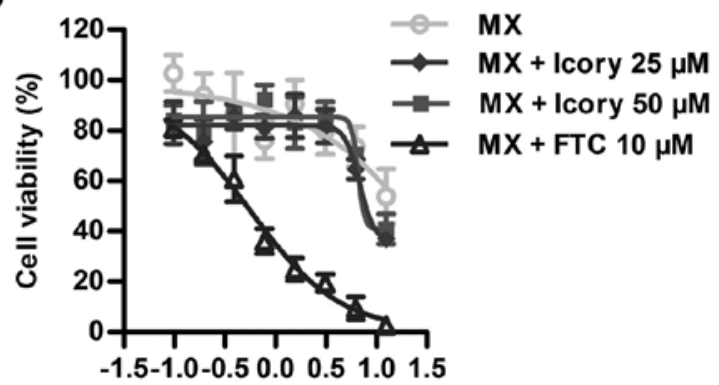

$\mathrm{MX}$ concentration ( $\log \mu \mathrm{M})$

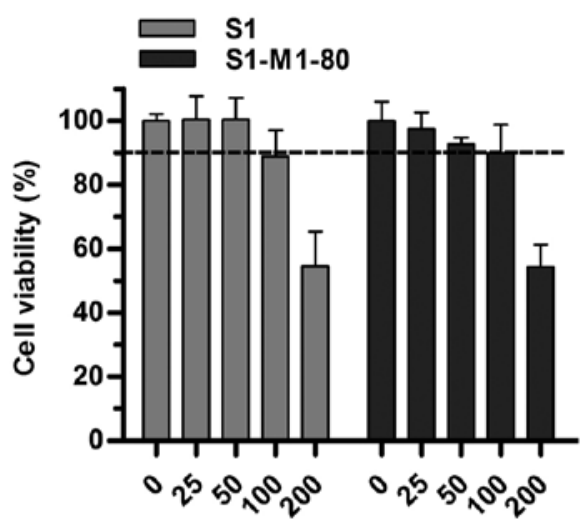

Icory concentration $(\mu \mathrm{M})$

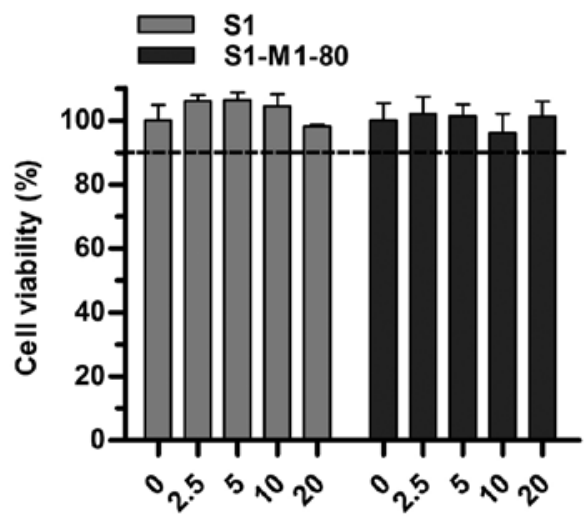

FTC concentration ( $\mu \mathrm{M})$

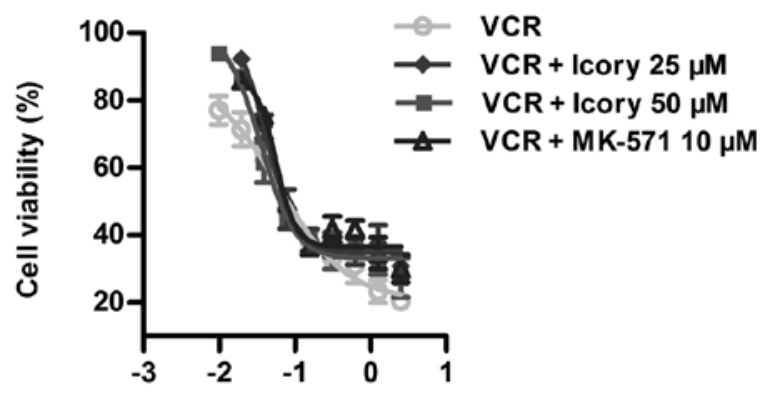

VCR concentration $(\log \mu \mathrm{M})$

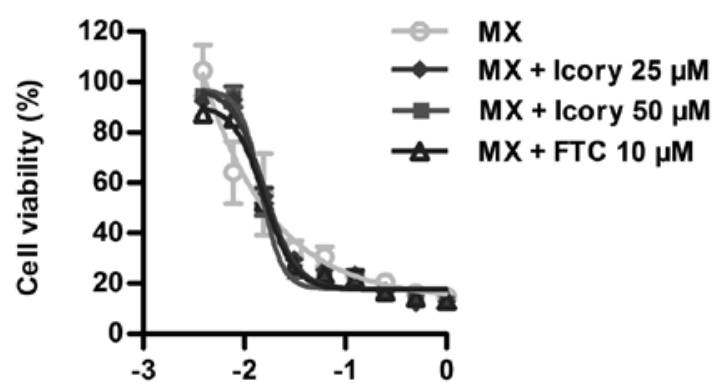

MX concentration $(\log \mu \mathrm{M})$

Figure 3. Icory does not sensitize ABCC1- or ABCG2-overexpressing cells to MX or VCR. (A) The percentage of surviving cells was measured after treatment with Icory, MK-571 and FTC for $72 \mathrm{~h}$ in HEK293/MRP1, S1-M1-80 cells and their parental cells by MTT assay, respectively. (B) The viability of HEK293/MRP1 cells (left panel) and HEK293/pcDNA3.1 cells (right panel) treated with VCR in the absence or presence of Icory ( 25 and $50 \mu \mathrm{M})$ was detected by the MTT assay. MK-571 (10 $\mu \mathrm{M})$ was used as a positive inhibitor of ABCC1. (C) The viability of S1-M1-80 cells (left panel) and S1 cells (right panel) treated with MX in the absence or presence of Icory $(25$ and $50 \mu \mathrm{M})$ was detected by the MTT assay. FTC $(10 \mu \mathrm{M})$ was used as a positive inhibitor of ABCG2. The results are presented as the means $\pm \mathrm{SD}$ of three independent experiments performed in six replicates.

Icory, FTC sensitized S1-M1-80 cells to MX at a non-toxic concentration of $10 \mu \mathrm{M}$ (Fig. 3C and Table IV). These results suggest that Icory may be a specific ABCB1 modulator.
Icory increases the intracellular accumulation of DOX in $A B C B 1$-overexpressing cells. To investigate the reversal mechanism by which Icory sensitizes ABCB1-mediated MDR 
A
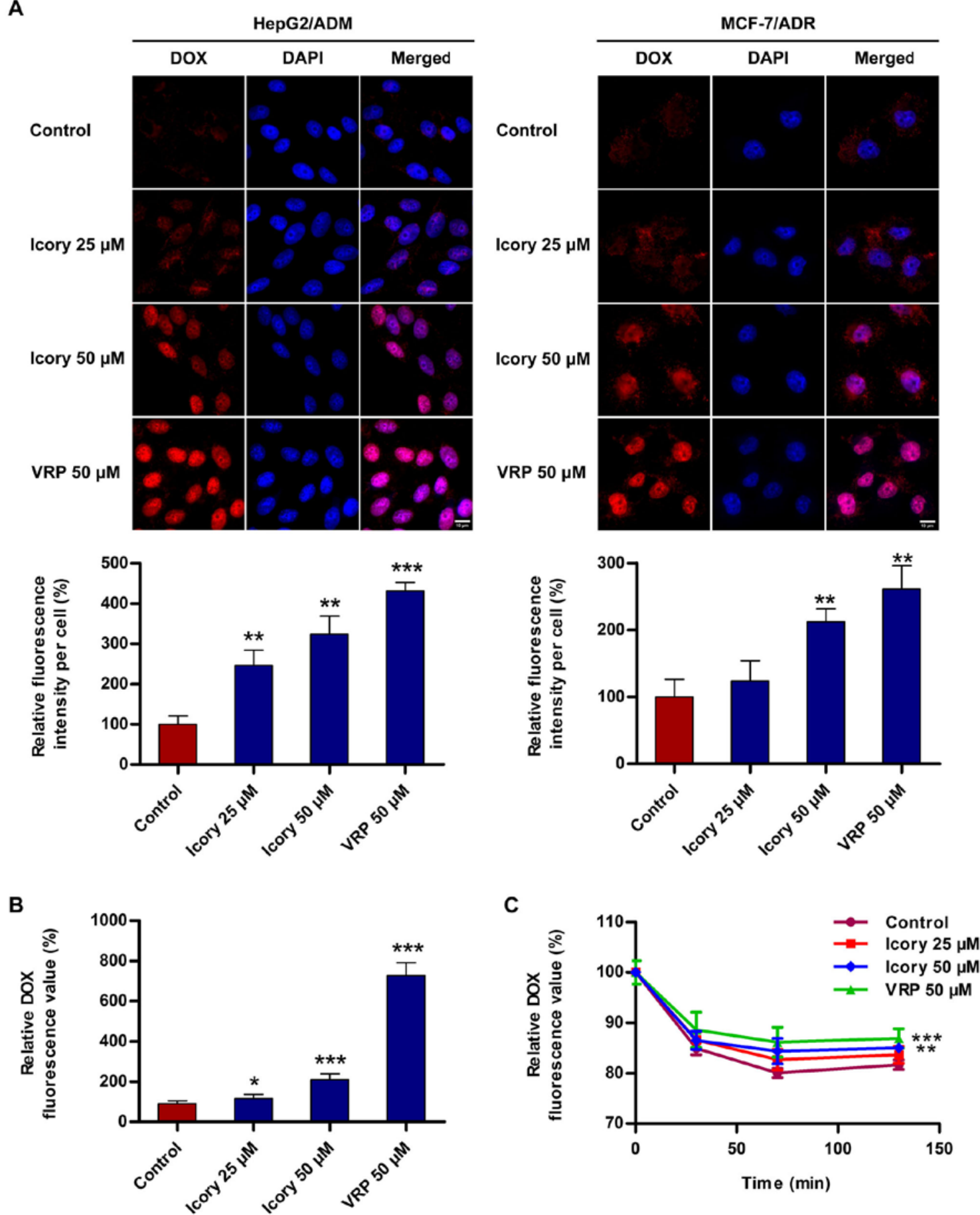

Figure 4. Icory increases the accumulation of DOX and inhibits the efflux of DOX in HepG2/ADM cells. (A) Cells were observed by fluorescence microscopy, and the representative images (top) and quantitative analysis (bottom) of DOX fluorescence are shown. DOX staining are shown in red. DAPI (blue) counterstains the nuclei. Original amplification: 630; bar: $10 \mu \mathrm{m}$. (B) The intracellular accumulation of DOX was measured with a DTX 880 Multimode Detector (C) The effect of Icory on DOX efflux in HepG2/ADM cells. The intracellular DOX level was measured using a DTX 880 Multimode Detector in different periods of time $(0,30,70$ and $130 \mathrm{~min})$. $\mathrm{VRP}(50 \mu \mathrm{M})$ was used as a positive-control inhibitor of ABCB1. The results are presented as the means $\pm \mathrm{SD}$ of three independent experiments. ${ }^{*} \mathrm{P}<0.05,{ }^{* *} \mathrm{P}<0.01$ and ${ }^{* * *} \mathrm{P}<0.001$ compared with the control.

in cancer cells, the accumulation level of DOX in ABCB1overexpressing cells was measured. As shown in Fig. 4A, Icory enhanced the intracellular fluorescence intensity of DOX in HepG2/ADM and MCF-7/ADR cells. A quantitation of the fluorescence intensity is presented with the images (Fig. 4A, bottom). Furthermore, a significant increase in the DOX intensity in the presence of Icory was detected using a Multimode Detector (Fig. 4B). The increase in DOX intensity mediated by
Icory was less than that of the positive-control VRP, in accord with their relative reversal activities. These results showed that Icory treatment elevates the intracellular DOX concentration in $\mathrm{ABCB} 1$-overexpressing cells.

Icory inhibits the intracellular efflux of DOX in $A B C B 1$ overexpressing cells. To investigate whether Icory can inhibit the efflux activity of ABCB1, a DOX efflux assay was 
A

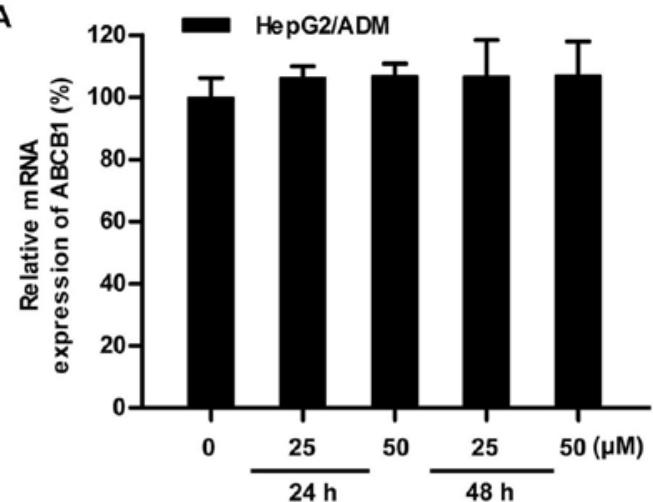

B

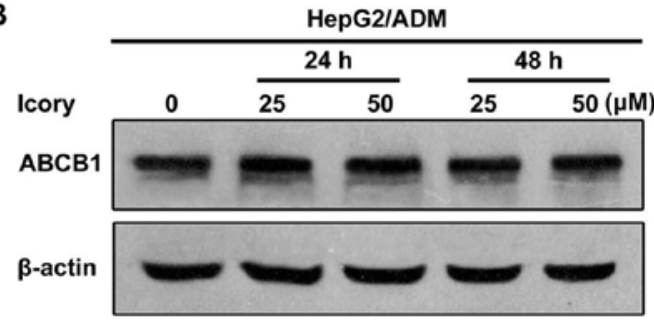

\begin{tabular}{ccccc} 
& \multicolumn{4}{c}{ MCF-7IADR } \\
\cline { 2 - 4 } \cline { 4 - 5 } Icory & 0 & $\frac{24 \mathrm{~h}}{25} \quad 50$ & & $\frac{48 \mathrm{~h}}{25} \quad 50(\mu \mathrm{M})$
\end{tabular}

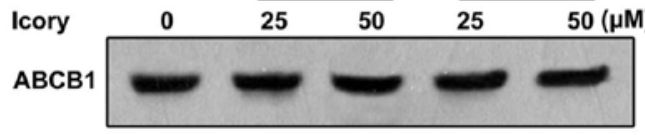

$\beta$-actin

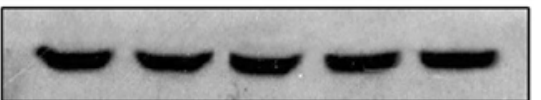

D

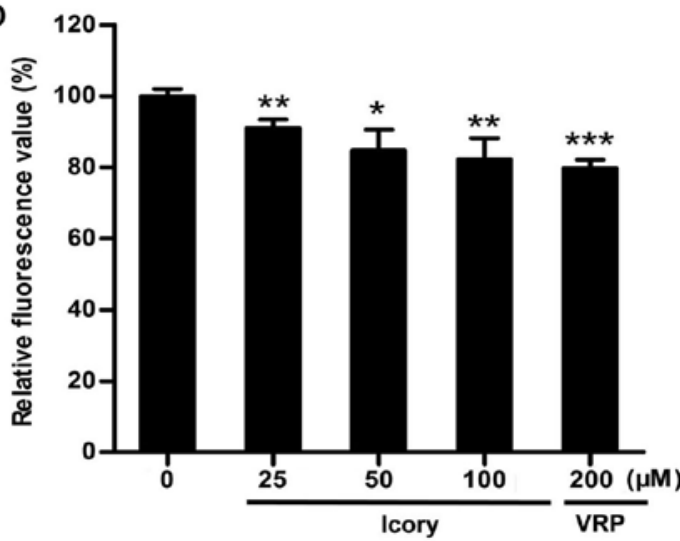

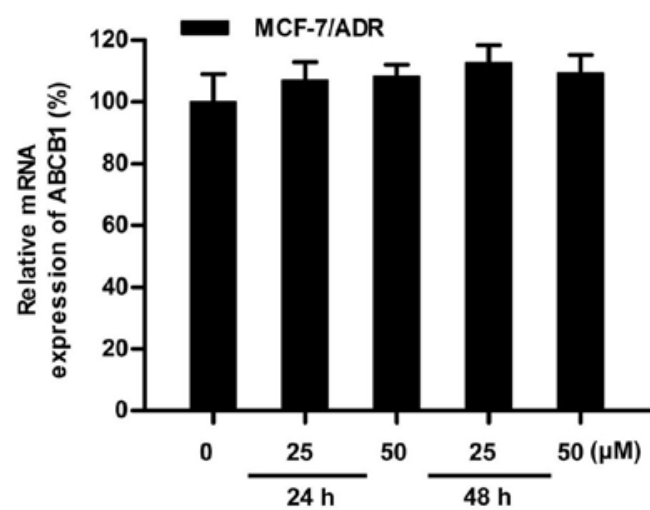

C
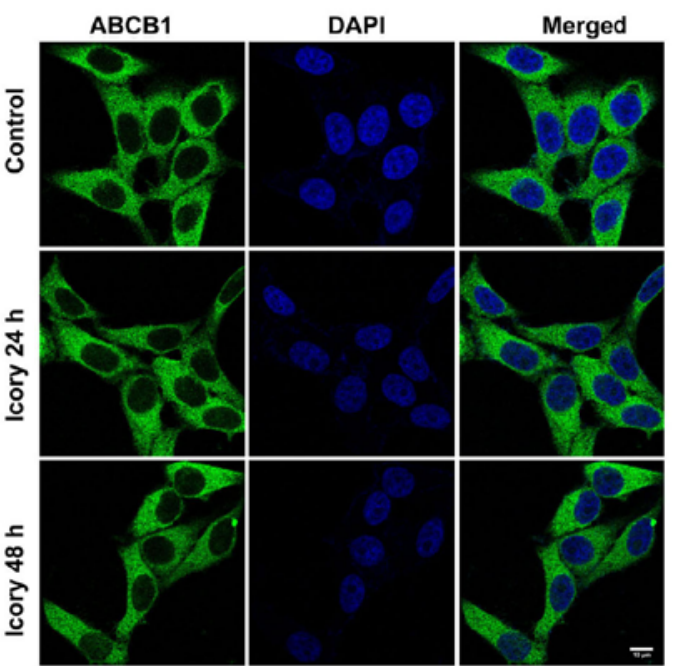

E

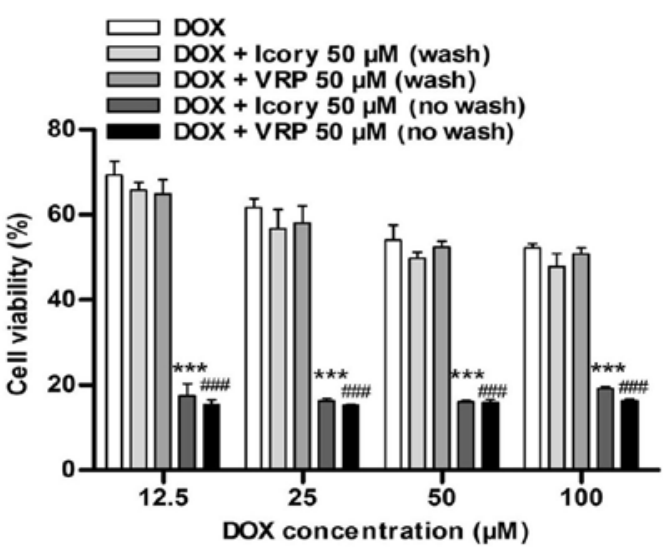

Figure 5. Icory stimulates ABCB1 ATPase activity but does not alter ABCB1 expression or localization; the MDR-reversal effect of Icory is reversible. (A) The effect of Icory at 25 and $50 \mu \mathrm{M}$ on the mRNA expression of ABCB1 in HepG2/ADM and MCF-7/ADR cells at 24 and $48 \mathrm{~h}$; GAPDH was used as an internal control. (B) Effect of Icory at 25 and $50 \mu \mathrm{M}$ on the protein expression of ABCB1 in HepG2/ADM and MCF-7/ADR cells at 24 and $48 \mathrm{~h}$; $\beta$-actin was used as an internal control. (C) Effect of Icory at $50 \mu \mathrm{M}$ on the localization of ABCB1 in HepG2/ADM cells for 24 and $48 \mathrm{~h}$. ABCB1 staining are shown in green. DAPI (blue) counterstains the nuclei. Original amplification, 630; bar, $10 \mu \mathrm{m}$. (D) The effect of Icory on ABCB1 ATPase activity was detected using the Pgp-Glo ${ }^{\mathrm{TM}}$ ATPase assay kit. VRP was used as a positive-control inhibitor of ABCB1. (E) Icory had no continued MDR-reversal effect after removal. The cells were pre-incubated with or without Icory $(50 \mu \mathrm{M})$ or VRP $(50 \mu \mathrm{M})$ for $24 \mathrm{~h}$; the compound was then washed out, and the cells were incubated with DOX for $72 \mathrm{~h}$. The viability of the cells was tested by the MTT assay. ${ }^{* * *} \mathrm{P}<0.001$ compared with the Icory-washout group and ${ }^{\# \#} \mathrm{P}<0.001$ compared with the VRP-washout group. Each point represents the mean $\pm \mathrm{SD}$ of at least three independent experiments performed in triplicate. ${ }^{*} \mathrm{P}<0.05,{ }^{* *} \mathrm{P}<0.01$ and ${ }^{* * * *} \mathrm{P}<0.001$ compared with the control.

performed with HepG2/ADM cells. As shown in Fig. 4C, the pumping rate of DOX in HepG2/ADM cells treated with Icory was lower than that in untreated cells. Consistent with their activities, VRP showed a stronger effect than Icory on the retention level of intracellular DOX. The results suggest that
Icory promotes DOX accumulation by blocking DOX efflux in ABCB1-overexpressing cells.

Icory has no effect on the expression of $A B C B 1$. Considering that blocking $\mathrm{ABCB} 1$ transport and downregulating $\mathrm{ABCB} 1$ 
Table IV. Reversal effect of Icory on SI-M1-80 and their parental sensitive cells.

$$
\left.\mathrm{IC}_{50} \pm \mathrm{SD}^{\mathrm{a}}(\mu \mathrm{M}) \text { (fold-reversal }{ }^{\mathrm{b}}\right)
$$

\begin{tabular}{lcc}
\cline { 2 - 3 } Treatments & S1-M1-80 & S1 \\
\hline MX & $14.3009 \pm 0.9842(1.00)$ & $0.0135 \pm 0.0074(1.00)$ \\
+ Icory $25 \mu \mathrm{M}$ & $6.3245 \pm 0.1678(1.72)$ & $0.0129 \pm 0.0092(1.05)$ \\
+ Icory $50 \mu \mathrm{M}$ & $8.3785 \pm 1.3797(1.72)$ & $0.0142 \pm 0.0080(0.95)$ \\
+ FTC $10 \mu \mathrm{M}$ & $0.4222 \pm 0.0231(33.87)$ & $0.0126 \pm 0.0057(1.07)$
\end{tabular}

${ }^{\text {aD }}$ ata in the table are shown as means \pm SD of at least three independent experiments performed in six replicates. ${ }^{\text {b}}$ The fold-reversals are calculated as $\mathrm{IC}_{50}$ for cells with the anticancer drugs in the absence of inhibitors divided by that in the presence of inhibitors.

expression would both result in the retention of intracellular DOX, we further examined the mRNA and protein expression levels of ABCB1. As shown in Fig. 5A and B, HepG2/ADM and MCF-7/ADR cells were treated with Icory at $25 \mu \mathrm{M}$ and $50 \mu \mathrm{M}$ for two time periods ( 24 and $48 \mathrm{~h}$ ). However, no significant alterations were observed in the ABCB1 mRNA or protein levels, confirming that the reversal effect of Icory is not related to the downregulation of $\mathrm{ABCB} 1$ expression.

Icory does not alter the localization of $A B C B 1$. In order to further investigate whether Icory can change cellular localization of ABCB1, the immunofluorescence assay was conducted in HepG2/ADM cells. As shown in Fig. 5C, Icory treatment for 24 or $48 \mathrm{~h}$ at $50 \mu \mathrm{M}$ did not alter the cellular localization of ABCB1.

Icory stimulates ABCB1 ATPase activity. We reasoned that Icory might induce DOX retention by inhibiting the efflux function of ABCB1. Thus, an ABCB1 ATPase activity assay was performed to investigate whether Icory is a substrate of ABCB1. According to the Pgp-Glo ${ }^{\mathrm{TM}}$ assay system, ABCB1 is an ATP-dependent drug efflux pump, and ATP consumption reflects its transport activity. As shown in Fig. 5D, similar to VRP, Icory strikingly stimulated ABCB1 ATPase activity in a concentration-dependent manner. The results indicate that Icory is likely a substrate of $\mathrm{ABCB} 1$ that blocks its efflux function.

The MDR-reversal effect of Icory depends on its durative concentration. A characteristic of an ABCB1 competitive inhibitor is that the reversal effect disappears following drug washout. The persistence and reversibility of MDR-reversal effects can be assessed in a therapeutically relevant way by assaying residual activity after washout of the reversal agents. As shown in Fig. 5E, the reversal effect of Icory on HepG2/ADM cells was no longer present after the washout of Icory, similar to VRP, a known ABCB1 competitive inhibitor. These results suggest that Icory may be a competitive inhibitor of ABCB1.

Molecular docking model of Icory binding to ABCB1. The above results suggested that the reversal effect of Icory may occur through a direct interaction with $\mathrm{ABCB} 1$. To further explore the probable binding conformation with $\mathrm{ABCB} 1$, Icory was computationally docked into $\mathrm{ABCB} 1$. As shown in Fig. 6, Icory bound to ABCB1 at the same site as VRP but did not completely overlap. The residues of ABCB1 surrounding Icory were LEU64, VAL861, ILE864, ALA865, ALA867, GLY868, THR941, GLN942, MET944, MET945, SER948, TYR949, ALA981, VAL984. Among these residues, LEU64, VAL861, ILE864, ALA865, GLY868, THR941, GLN942, MET945, TYR949, ALA981, VAL984 were also around VRP. These residues were well consistent with the key residues. The docking result further confirmed that Icory binds to ABCB1 at the same site as VRP but that the binding site does not completely overlap with that of VRP. In addition, the binding energy between icory or VRP and ABCB1 was $46.55 \mathrm{kcal} / \mathrm{mol}$ and $123.5 \mathrm{kcal} / \mathrm{mol}$, respectively, which suggested the affinity of Icory binding to ABCB1 may be weaker than that of VRP.

\section{Discussion}

In the past three decades, researchers have devoted much effort to the search for effective and clinically applicable ABCB1 modulators. Searching for more effective, low-toxicity ABCB1 modulators from traditional Chinese medicine has become a promising road. Uncaria alkaloids, the major naturally active substances of uncaria, were reported to have anticancer activity, including cytotoxicity and MDR-reversal effects. Uncaria is a common traditional Chinese medicine, and there are different constituents and contents with the change of uncaria species. The six alkaloids are principal components which exist in great quantities ranging from $0.1 \%$ to $1 \%$ in uncaria $(17,18)$. In this investigation, we demonstrated for the first time that all six alkaloids significantly reduced the resistance of ABCB1mediated MDR cells to chemotherapeutics, also, the total uncaria alkaloid extract exhibits MDR reversal activity with 8.74 reversal-fold value in HepG2/ADM cells when combined with DOX.

Furthermore, HS and HST showed higher cytotoxicity against ABCB1-overexpressing cells than the other four agents, likely due to differences in their chemical structures. Compared with HS and HST, which are non-oxindole alkaloids, Rhy, Irhy, Cory and Icory are oxindole alkaloids characterized by oxidization at the indole ring, this distinction may explain their weaker toxicity than HS and HST. By contrast, Rhy/ Irhy and Cory/Icory are two pairs of isomerides, and they contain a spirocyclic ring on the indole ring but have varying stereochemistry on the ring skeleton, which may be connected with their MDR-reversal effect. Therefore, the selection of a suitable uncaria alkaloid chemotype may be very important for MDR-reversal activity because it differs from the chemical structure and conformation.

Since some MDR transporter inhibitors not only bind to $A B C B 1$ but also influence the function of other $A B C$ transporters, they do not exhibit specificity. Icory sensitized ABCB1-overexpressing cells to DOX, VCR and paclitaxel, but it did not have similar effect on their parental cells. Icory did not alter the sensitivity of ABCB1-overexpressing cells to cisplatin, which is not an $\mathrm{ABCB}$ 1 substrate, suggesting that the reversal potency of Icory is closely associated with ABCB1. As previously reported, $\mathrm{ABCC} 1$ can remove internal noxious 
A

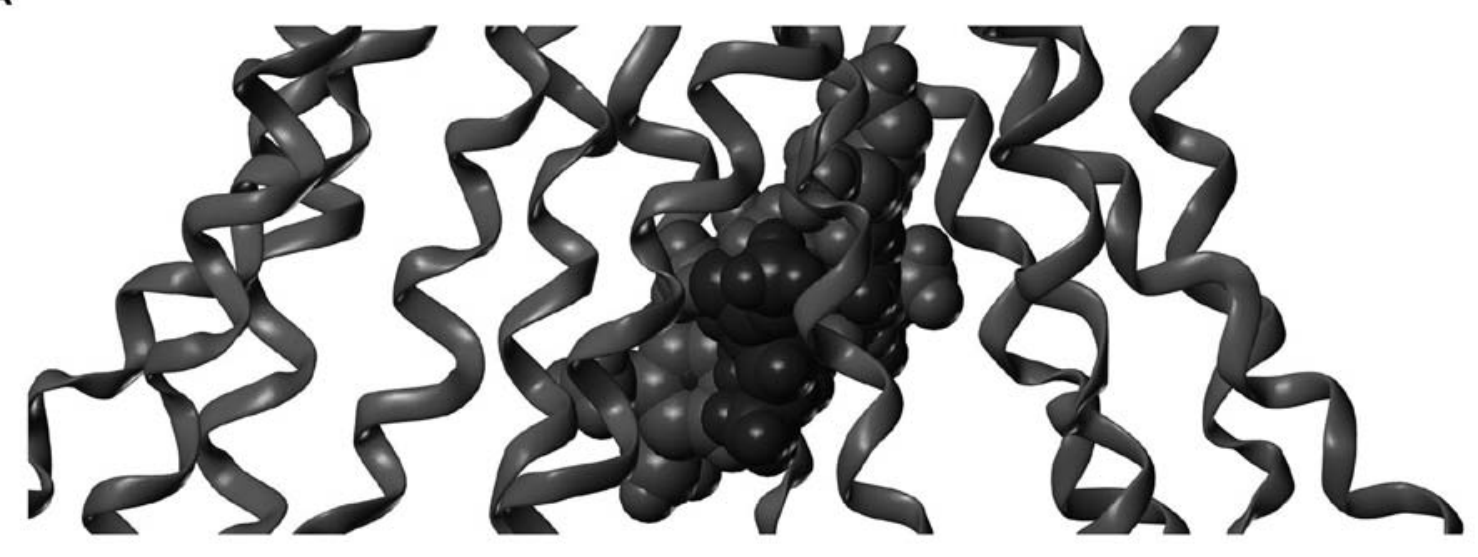

B

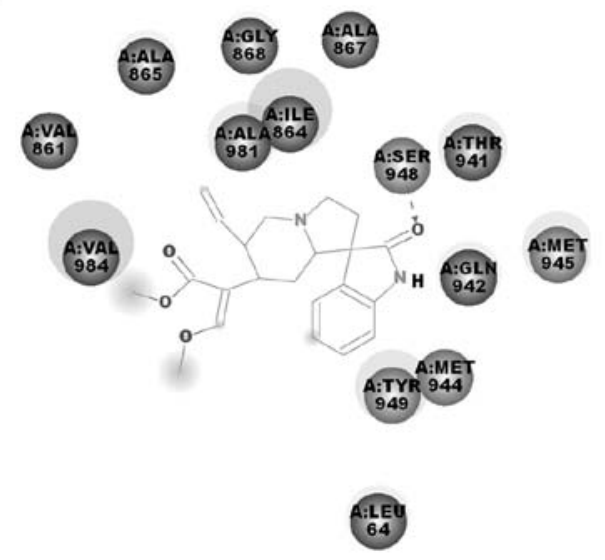

C

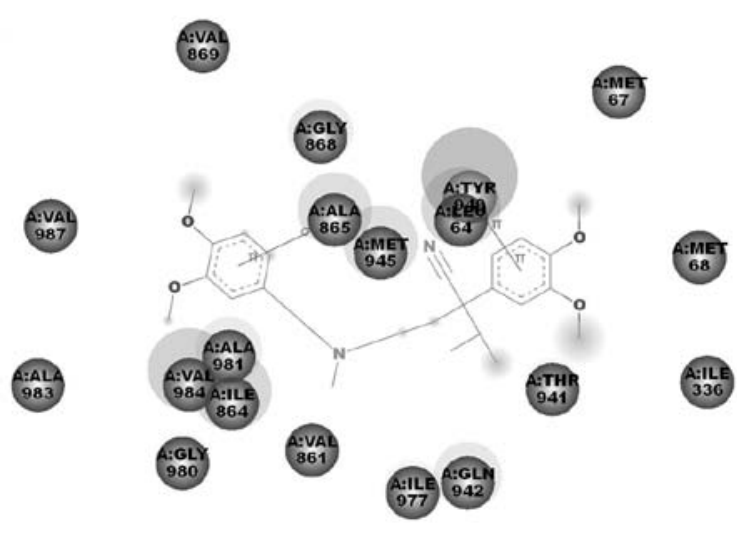

Figure 6. Docking analysis of Icory and VRP binding to ABCB1. (A) The binding mode and position of Icory and VRP with ABCB1. The residual amino acids around Icory (B) and VRP (C). Key residues are labeled.

substances, including important endogenous substances, xenobiotics and their metabolites, to protect normal tissue from cytotoxicity (19). ABCG2 confers a protective effect to hypoxic cells, and ABCG2 is also responsible for cellular homeostasis and influences medicine absorption, distribution, and excretion in the human body (20-23). Thus, inhibiting ABCC1 and ABCG2 may disrupt cellular homeostasis and normal drug metabolism, potentially causing toxicity and other side effects. Fortunately, Icory had no significant reversal effects on ABCC1- and ABCG2-overexpressing cells or their parental cells. Therefore, the use of Icory would minimize any side effects caused by the inhibition of ABCC1 and ABCG2 transporters.

Icory significantly increased intracellular DOX accumulation in ABCB1-overexpressing cells, and the efflux assay confirmed that the DOX accumulation was due to the inhibition of $\mathrm{ABCB} 1$ efflux function. As previously reported, downregulation of $\mathrm{ABCB} 1$ expression would result in the inhibition of $\mathrm{ABC}$ transporter-mediated efflux (24). However, our results showed that after treatment with Icory, neither the expression levels nor localization of ABCB1 in HepG2/ADM or MCF-7/ADR cells were significantly altered, suggesting that Icory influences the drug transport function rather than the expression and localization of ABCB1. It is well known that the substrates of ABCB1 activate the ATPase to hydrolyze ATP and provide the energy needed by the
ABCB1 transporter. Therefore, a change in ABCB1 ATPase activity directly reflects whether a drug is the substrate of ABCB1. Our results showed that Icory markedly stimulated the activity of the ABCB1 ATPase in a concentrationdependent manner, indicating that Icory may be a substrate of the ABCB1 transporter. As previously reported, an ATP modulator can act as a competitive inhibitor by binding to the drug-binding pocket in TMD or as a non-competitive inhibitor by suppressing ATP binding by nucleotide-binding domains (25). Our results showed that the reversal activity of Icory disappeared after being washed out, resembling the positive-control VRP and indicating that Icory acts as a competitive inhibitor of ABCB1. Moreover, our molecular docking analysis indicated that the residues of $\mathrm{ABCB} 1$ surrounding Icory also partly overlapped with those around VRP. The result further supports the idea that Icory binds to important binding sites of ABCB1 and acts as a substrate of ABCB1.

Icory has several particular characteristics comparing to other MDR inhibitors. The six uncaria alkaloids all derive from the low toxic traditional Chinese medicine uncaria, which has been used in clinic for a long time, and they exist in great quantities in uncaria; Icory can specifically reverse ABCB1 other than ABCC1 or ABCG2 transporter-mediated MDR cancer. However, compared with the tyrosine kinase inhibitors, the reversal activity of Icory is still weaker. Thus, 
in order to improve the efficacy of uncaria alkaloid, further structural modification studies are warranted.

In this study, we demonstrated that uncaria alkaloids, including Rhy, Irhy, Cory, Icory, HS and HST, reverse ABCB1mediated MDR at non-toxic concentrations. Among them, Icory showed the strongest activity. Instead of altering the expression level and localization of ABCB1, Icory acts as a substrate of $\mathrm{ABCB} 1$, competitively binding to the drug-binding sites of $\mathrm{ABCB} 1$ and thus inhibiting its drug efflux function. The uncaria alkaloids exhibit potential to be reversal agents for $\mathrm{ABCB} 1$ transporter-mediated MDR, and further in vivo studies are warranted.

\section{Acknowledgements}

Special thanks to Professor Kwok-Pui Fung (The Chinese University of Hong Kong, Hong Kong) for HepG2 and HepG2/ADM cells, Professor Li-Wu Fu (Sun Yat-Sen University, China) for MCF-7 and MCF-7/ADR cells, Dr Suresh Ambudkar (NCI, NIH, Bethesda, MD, USA) for HEK293/pcDNA3.1 and HEK293/MRP1 cells, Dr Susan Bates and Robert Robey (NCI, NIH) for S1 and S1-M1-80 cells. This work was supported by the National Science Foundation of China (81573455), the Science and Technology Cooperation Research Project of Chinese Traditional Medicine Industry for Jianhe County, Guizhou Province, 2014 (sponsored by the Bureau of Science and Technology of Jianhe county, no. 4/no. 5).

\section{References}

1. Li W, Zhang H, Assaraf YG, Zhao K, Xu X, Xie J, Yang DH and Chen ZS: Overcoming ABC transporter-mediated multidrug resistance: Molecular mechanisms and novel therapeutic drug strategies. Drug Resist Updat 27: 14-29, 2016.

2. Zhang K, Mack P and Wong KP: Glutathione-related mechanisms in cellular resistance to anticancer drugs. Int J Oncol 12: 871-882, 1998

3. Dean M, Hamon Y and Chimini G: The human ATP-binding cassette (ABC) transporter superfamily. J Lipid Res 42 : 1007-1017, 2001.

4. Tiwari AK, Sodani K, Dai CL, Ashby CR Jr and Chen ZS: Revisiting the ABCs of multidrug resistance in cancer chemotherapy. Curr Pharm Biotechnol 12: 570-594, 2011.

5. Gottesman MM, Fojo T and Bates SE: Multidrug resistance in cancer: Role of ATP-dependent transporters. Nat Rev Cancer 2: 48-58, 2002.

6. Sarkadi B,Homolya L, Szakács G and Váradi A: Human multidrug resistance $\mathrm{ABCB}$ and $\mathrm{ABCG}$ transporters: Participation in a chemoimmunity defense system. Physiol Rev 86: 1179-1236, 2006.

7. Szakács G, Paterson JK, Ludwig JA, Booth-Genthe C and Gottesman MM: Targeting multidrug resistance in cancer. Nat Rev Drug Discov 5: 219-234, 2006.

8. Ambudkar SV, Dey S, Hrycyna CA, Ramachandra M, Pastan I and Gottesman MM: Biochemical, cellular, and pharmacological aspects of the multidrug transporter. Annu Rev Pharmacol Toxicol 39: 361-398, 1999.
9. Yanagisawa T, Newman A, Coley H, Renshaw J, Pinkerton CR and Pritchard-Jones K: BIRICODAR (VX-710; Incel): An effective chemosensitizer in neuroblastoma. Br J Cancer 80 : 1190-1196, 1999.

10. Rowinsky EK, Smith L, Wang YM, Chaturvedi P, Villalona M, Campbell E, Aylesworth C, Eckhardt SG, Hammond L, Kraynak M, et al: Phase I and pharmacokinetic study of paclitaxel in combination with biricodar, a novel agent that reverses multidrug resistance conferred by overexpression of both MDR1 and MRP. J Clin Oncol 16: 2964-2976, 1998.

11. Leonard GD, Fojo T and Bates SE: The role of ABC transporters in clinical practice. Oncologist 8: 411-424, 2003.

12. Leonard GD, Polgar O and Bates SE: ABC transporters and inhibitors: New targets, new agents. Curr Opin Investig Drugs 3: 1652-1659, 2002.

13. Cui Y: Advances in study on chemical compositions and pharmacological activities of Uncaria rhynchophylla. J Xi'an Univ (Natural Science Edition) 18: 16-18, 2015 (In Chinese).

14. He Y: Pharmacological development of ramulus Uncariae cum uncis and its active ingredients. Shanghai Univ Tradit Chin Med 37: 57-60, 2003 (In Chinese).

15. Ndagijimana A, Wang X, Pan G, Zhang F, Feng H and Olaleye O: A review on indole alkaloids isolated from Uncaria rhynchophylla and their pharmacological studies. Fitoterapia 86: 35-47, 2013.

16. Liu DL, Li YJ, Yao N, Xu J, Chen ZS, Yiu A, Zhang CX, Ye WC and Zhang DM: Acerinol, a cyclolanstane triterpenoid from Cimicifuga acerina, reverses ABCB1-mediated multidrug resistance in HepG2/ADM and MCF-7/ADR cells. Eur J Pharmacol 733: 34-44, 2014.

17. Zhang J, Yang CJ and Wu DG: Studies on the chemical constituents of sharpleaf gambir plant (Uncaria rhynchophylla) (II). Chin Tradit Herbal Drugs 29: 649-651, 1998.

18. Yamanaka E, Kimizuka Y, Aimi N, Sakai S and Haginiwa J: Studies of plants containing indole alkaloids. IX. Quantitative analysis of tertiary alkaloids in various parts of Uncaria rhynchophylla MIQ. Yakugaku Zasshi 103: 1028-1033, 1983 (In Japanese)

19. He SM, Li R, Kanwar JR and Zhou SF: Structural and functional properties of human multidrug resistance protein 1 (MRP1/ ABCC1). Curr Med Chem 18: 439-481, 2011.

20. Krishnamurthy P and Schuetz JD: The role of ABCG2 and ABCB6 in porphyrin metabolism and cell survival. Curr Pharm Biotechnol 12: 647-655, 2011.

21. Ye L, Lu L, Li Y, Zeng S, Yang X, Chen W, Feng Q, Liu W, Tang L and Liu Z: Potential role of ATP-binding cassette transporters in the intestinal transport of rhein. Food Chem Toxicol 58: 301-305, 2013.

22. Babu K, Zhang J, Moloney S, Pleasants T, McLean CA, Phua SH and Sheppard AM: Epigenetic regulation of ABCG2 gene is associated with susceptibility to xenobiotic exposure. J Proteomics 75: 3410-3418, 2012.

23. Kummu M, Sieppi E, Wallin K, Rautio A, Vähäkangas K and Myllynen P: Cadmium inhibits ABCG2 transporter function in BeWo choriocarcinoma cells and MCF-7 cells overexpressing ABCG2. Placenta 33: 859-865, 2012.

24. Tang SJ, Chen LK, Wang F, Zhang YK, Huang ZC, To KK, Wang XK, Talele TT, Chen ZS, Chen WQ, et al: CEP-33779 antagonizes ATP-binding cassette subfamily B member 1 mediated multidrug resistance by inhibiting its transport function. Biochem Pharmacol 91: 144-156, 2014.

25. Aller SG, Yu J, Ward A, Weng Y, Chittaboina S, Zhuo R, Harrell PM, Trinh YT, Zhang Q, Urbatsch IL, et al: Structure of P-glycoprotein reveals a molecular basis for poly-specific drug binding. Science 323: 1718-1722, 2009. 